\title{
Música, Plástica y Museo de Bellas Artes a través de un proyecto de diseño digital
}

\section{Music, Art and Fine Arts Museum through a digital design project}

\author{
Inés López Manrique \\ lopezines@uniovi.es \\ Míriam Perandones Lozano \\ perandones@uniovi.es \\ Sandra Susana Pires Silva Palhares \\ sandrapalhares@ie.uminho.pt
}

\section{RESUMEN}

El presente artículo muestra la experiencia de trabajo de la asignatura Taller interdisciplinar de Música y Plástica, perteneciente al Máster Universitario en Formación del Profesorado de Educación Secundaria Obligatoria, Bachillerato y Formación Profesional de una universidad pública del norte de España. La naturaleza de la materia llevó a centrar el trabajo en acciones de sinestesia en el mundo físico. La realización de una experiencia que recogiera sinestesias y proyecto de diseño con la utilización de herramientas digitales supuso una fórmula de trabajo grupal que eliminó los miedos a las carencias de conocimientos y facilitó el trabajo interdisciplinar.

Palabras clave: Plástica, Música, Taller Interdisciplinar, Herramientas Digitales, Máster Universitario

\section{ABSTRACT}

This article presents the work experience of the subject Interdisciplinary Workshop of Music and Art, belonging to the University Master's Degree in Teacher Training of Compulsory Secondary Education, Baccalaureate and Vocational Training of a public university in northern Spain. The nature of the subject led to focusing work on synesthesia actions in the physical world. The realization of an experience that gathered synesthesia and design project with the use of digital tools was a formula for group work that eliminated fears of deficiencies of knowledge and facilitated interdisciplinary work.

Keywords: Art, Music, Interdisciplinary Workshop, Digital Tools, Master's Degreet 


\section{Introducción}

Estamos inmersos en un mundo cada vez más digitalizado, por lo que abordar la Educación Musical y la Educación Plástica y Visual en el contexto educativo actual implica necesariamente tratar las herramientas digitales. Esto no implica perder otro tipo de herramientas y experiencias, ya que como explica Saura (2015) nos encontramos viviendo simultáneamente en una realidad física y otra virtual, lo cual se refleja en la utilización de herramientas tradicionales y digitales simultáneamente en las prácticas pedagógicas actuales.

En menos de diez años se ha visto esta vertiginosa necesidad, dándose también una evolución general en el escenario educativo, donde se está llevando el desarrollo de primeras experiencias con aspectos digitales ya desde el nivel de Educación Infantil. Es importante señalar que estas prácticas se planifican en relación a otras cuestiones como las inteligencias múltiples y el trabajo grupal (Amante y Faria, 2012; Cosme y Tomás, 2015), lo que también es un síntoma de los cambios que se están aplicando.

La presente propuesta didáctica se enmarca en la asignatura optativa Taller interdisciplinar de Música y Plástica, perteneciente al Máster Universitario en Formación del Profesorado de Educación Secundaria Obligatoria, Bachillerato y Formación Profesional de una universidad pública del norte de España. El grupo de estudiantes está formado por diez personas graduadas en estudios de los ámbitos plástico y musical. Por lo que el carácter optativo de la asignatura y el reducido número de alumnos, ya especialistas, facilita la realización de experiencias destinadas a la docencia en educación secundaria y la experimentación.

En relación con los objetivos principales, como docentes de esta materia, se intenta desarrollar una asignatura de utilidad educativa para los futuros profesores en la que se ponga en práctica las competencias que la guía docente marca. Para conseguir esto se plantean unas actividades previas a los estudiantes con carácter inicial y de afianzamiento. Posteriormente se les propone el diseño de un plan de trabajo, destinado a alumnos de Educación Secundaria Obligatoria (E.S.O.) y Bachillerato, donde se integren la Educación Plástica y Visual junto a la Educación Musical. Por último, la planificación es presentada en grupo junto con el que se desarrolla un debate que lleva a hacer modificaciones e incorporar nuevas ideas antes de la entrega.

Habitualmente los temas que se abordan en la materia conciernen a aspectos relacionados con los proyectos educativos en el ámbito artístico y la inclusión de aspectos culturales. Y también sobre la relación entre la expresión musical y plástica en

talleres de expresión, así como la construcción personal y colectiva del conocimiento artístico. Durante los años 2015 a 2019, se ha observado una evolución en la forma de desarrollar la docencia y en las propias demandas de los estudiantes. Así pues, las posibilidades de lo digital para el desarrollo del proyecto se han convertido en interés y objeto de la asignatura.

En un inicio, el desarrollo del programa estuvo centrado, principalmente, en ejercicios de transformación o traducción entre los productos Plásticos y Musicales. Concretamente el trabajo para la transformación músico-plástica, o viceversa, para lo cual se compartían las directrices dictadas por Cristiá (2012). Esta autora señaló cinco niveles de trabajo: emocional, material, morfológico, textural y conceptual. Como ejemplo se explica a continuación una forma de trabajo con operaciones planteadas para transformar una melodía en un dibujo o un dibujo en melodía.

El trabajo a nivel emocional se destina a escuchar una pieza musical y a partir de ella dibujar y pintar intentando traducir la música al dibujo o pintura. En el nivel material se analiza la sintaxis de los elementos propios del lenguaje musical y plástico de acuerdo a las teorías de autores como Kandinsky (1996, 1998), Dondis (2000), García-Sipido y Lago (1996) o Toch (2001). La estructura de las obras y su imitación en alguno de los dos lenguajes se desarrolla en el nivel morfológico, donde se considera si la relación entre los materiales es sincrónica o no en el nivel textural. Finalmente, el aspecto conceptual se tratará cuando en el traslado de la obra de un campo a otro se trabaje el concepto o idea.

Si bien estos niveles de desarrollo, y con ello de los planteamientos de los ejercicios, pueden reducirse a tres planos, suele trabajarse con los cinco. En el caso de la simplificación se les indica a los estudiantes la existencia de un primer nivel de tipo emocional vinculado con actividades que manejan lo expresivo, un segundo de representación conceptual o simbolización y por último un plano textural o adecuado a las acciones de sinestesia. 
Pero el trabajo con la asignatura ha llevado a traspasar esta primera noción de trabajos de transformación centrados en el mundo físico y adentrarse en más formas de trabajo. Particularmente en este caso, aunque inicialmente lo sensorial, la corporalidad y el simbolismo fueron suficientes para afrontar estos los lenguajes plástico y musical, se encontró que además de desarrollar la línea de acción física era necesario vincularse más con las acciones digitales.

$Y$ es que en relación con las nuevas tecnologías se ha observado en el aula, y durante este tiempo de trabajo, un cambio en las demandas de los estudiantes, siendo las cuestiones digitales una prioridad. Conviene subrayar que en la medida en que se ha sentido esa evolución respecto a la demanda tecnológica, el carácter de taller de la asignatura también ha llevado a plantear una metodología por proyectos más flexible y adaptada a los estudiantes.

A su vez, otras universidades han ofrecido asignaturas que integran varias áreas artísticas, como lo ha hecho la Universidad de Sevilla. En relación a esta experiencia Gutiérrez y Díaz (2002) señalaban la importancia de crear un planteamiento donde se relacionen los saberes entre estas artes y no el crear un conocimiento sumatorio pero independiente. Es ahí donde el trabajo interdisciplinar se revela más claramente, aunque en el ámbito universitario no es frecuente (Carbajal, 2010; Zárate, 2007).

\section{Metodología}

La asignatura se desarrolla durante once sesiones de dos horas, en primer lugar, se propuso trabajar los conceptos teóricos de forma práctica según las indicaciones de señaladas anteriormente en cuatro sesiones. Posteriormente se delegaron las seis sesiones restantes para el nuevo proyecto, reservando una séptima para las presentaciones.

La propuesta se planteó como un proyecto de diseño gráfico y audiovisual para el Museo de Bellas Artes, a partir del desarrollo de una logomarca (tipografía y símbolo) y su presentación musicalizada a modo de las animaciones introductorias en internet, productos audiovisuales y televisión.

Se conformaron tres grupos de estudiantes que combinaban alumnos de las ramas de Plástica y Música, se entendió el proceso de trabajo según los pasos del proceso del Diseño. Para ello se revisó la metodología del proyecto (Frascara, 2006) y se organizaron las fases a seguir: encargo del trabajo
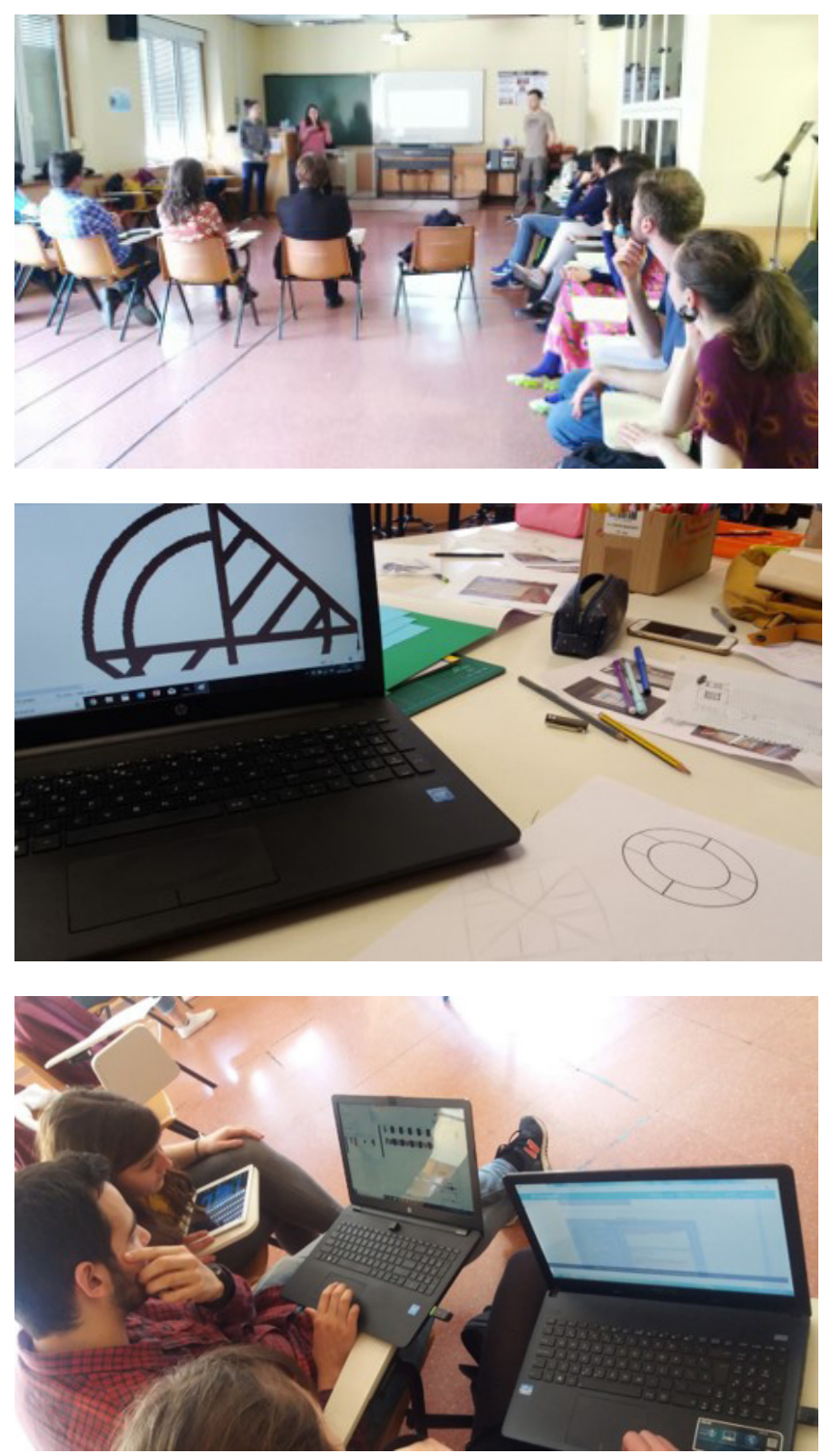

Figuras 1, 2 y 3. Proceso de diseño y presentación del proyecto.

por el profesorado o primera definición del problema; análisis, interpretación y organización de la información; Especificaciones para la visualización tercera definición del problema (desarrollo del anteproyecto, presentación al cliente, organización de la producción e implementación) y por último verificación del diseño.

El papel del cliente en este caso lo haría un jurado formado por el director del museo, dos profesores especializados externos y las docentes de la asignatura. Lo que conecta la experiencia con la realidad del cliente y el mundo laboral. También se requirió de una

memoria o justificación escrita que no excediera de tres páginas con imágenes incluidas, recomendando un estilo de redacción concreto, sencillo y sin reiteraciones. 
En la memoria se incluiría: Descripción y significado básico de los elementos diseñados que identifican al museo (símbolo o imagen y tipografía) y de los sonidos o composición musical; Descripción detallada de elementos; Significado de esos elementos y estructura de la composición plástica y musical; Breve explicación sobre el conjunto de los elementos de la animación; Esquema del proceso de ideación y justificación de las decisiones tomadas, pudiendo aportarse fotografías del museo y las obras que han inspirado los diseños, imágenes del proceso, opiniones de cada uno de los integrantes del grupo, otros logos que han servido de inspiración, bocetos previos, pruebas de sonido y color, etc.

A lo largo de las instrucciones o briefing se especificó que las imágenes podrían reflejar elementos alusivos al contenido y continente del museo (espacios y detalles arquitectónicos, elementos de obras pictóricas y escultóricas, piezas de diseño artesanal e industrial, etc.)

Se realizó una visita virtual al museo y otra presencial para conocer el edificio y sus obras, durante la misma se realizaron fotografías y vídeos que fueron descargados en un Google Drive grupal, igualmente los estudiantes crearon un grupo utilizando las redes sociales de Facebook, Instagram y WhatsApp para intercambiar materiales.

Además de fotografías se recomendó recoger información por medio del dibujo, para ello utilizaron cuadernos de dibujo y lápices tradicionales, así como smartphones y tabletas digitales. A través de las aplicaciones Sketchbook y Corel Painter en el entorno Android y con Adobe Photoshop Sketch y los servicios propios del entrono Apple que otorgan iPad e iPhone, se registraron algunos elementos del museo.

Las cuestiones sonoras y musicales también fueron objeto de estudio dentro del museo, haciendo registros de las mismas a través de las propias grabadoras de los dispositivos digitales y de aplicaciones como Easy Voice Recorder y Parrot.

Posteriormente el montaje audiovisual fue realizado con los programas Windows Movie maker, Scratch, Lightworks, Mixed DJ y Edjing.

\section{Resultados}

Además de una formación interdisciplinar la asignatura y la integración de actividades relacionadas con nuevas tecnologías demostró unos beneficios en los estudiantes y el profesorado. En el caso de los estudiantes: El trabajo se desarrolló en grupo y supuso un enriquecimiento personal pleno; Se produjo un intercambio de papeles y competencias; , aquellos estudiantes con facilidad para el dibujo unían sus fuerzas a los que presentaban capacidades para la música, pero el hecho de utilizar tecnologías digitales les hacía atreverse a intervenir en lo que "no era su campo"; Se observó una ampliación de horizontes en relación a los referentes visuales y musicales a utilizar y conocer; $\mathrm{Al}$ tratarse de una aproximación a lo que será la colaboración real entre docentes, los recursos digitales ayudaron a producir la cercanía y con ello poder ver trasladada esta experiencia una vez terminada la etapa de estudiantes cuando entren en el mercado laboral; Conexión con el mundo profesional facilitando la presentación de trabajos con un buen acabado; "Descanso" de asignaturas más teóricas y proyección de la creatividad en un trabajo grupal.

A su vez, en el profesorado se obtienen beneficios como: Trabajo interdisciplinar real en el contexto universitario con herramientas digitales; Mayor interacción entre los pares ya que la dinámica requiere máxima comunicación y flexibilidad entre las docentes; Resulta necesaria cierta elasticidad en los horarios reajustando el calendario; Generación de sinergias enriquecedoras, aprendizaje en relación a los posibles proyectos digitales y previsión de plazos y recursos para próximos cursos; La acción pedagógica se convierte en una actividad más creativa.

\section{Conclusiones}

Como resultado podemos afirmar que las asignaturas ofertadas en el Máster de Formación del Profesorado están centradas en los aspectos didácticos, pero no desarrollan la creatividad artística a nivel de producción personal, por lo que la asignatura goza de muy buena acogida. El grupo de alumnos procedentes de estudios musicales se enriquecen con las actividades plástico visuales y a la inversa, siendo en ocasiones la primera vez que hacen una inmersión en ese campo. Lo que esto posibilita que posteriormente trasladen esta actividad a la labor docente en los centros de educación.

En síntesis, las actividades de carácter innovador atraen a los estudiantes implicándoles en su realización, el hecho de aplicar las nuevas tecnologías refuerza ese carácter renovador. El próximo reto es promover más actividades en esta dirección y potenciar la preparación del profesorado en estas cuestiones. 
Finalmente, indicar, respecto al profesorado, y haciendo referencia a experiencias didácticas entre música y plástica, QUE la coordinación entre las distintas materias no es habitual en la enseñanza universitaria (Carvajal, 2010; Gutiérrez y Díaz, 1993; Zárate, 2007). Porque suelen tratarse de espacios de aprendizaje diferenciados, pero no interconectados, en este caso la presente asignatura se desarrolla con una voluntad de integración de saberes e interdisciplinariedad verdadera además de la integración con otras áreas.

\section{Referencias}

Amante, L., \& Faria, Á. (2012). Sentido (s) emergente (s) das tecnologias digitais no jardim de infância. Ensinar e aprender online com tecnologias digitais: abordagens teóricas e metodológicas (45-62). Porto: Porto Editora.

Carbajal, Y. (2010). Interdisciplinariedad: desafío para la educación superior y la investigación. Revista Luna Azul, (31), 156-169.

Gutiérrez, R. \& Díaz, M. D. (1993). Representación plástico musical de carácter docente: una innovación educativa en la enseñanza universitaria. Revista de Enseñanza Universitaria, 6, 105-110.

Gutiérrez, R. \& Díaz, M. D. (2002). Música y Plástica: globalización en la formación propedéutica de los futuros maestros. Una innovación en la enseñanza universitaria. Revista Electrónica de LEEME, (11).

Gutiérrez, C.J. \& Izquierdo, T. (2015). Experiencias y recursos de innovación en Educación Infantil. Murcia: Universidad de Murcia, Servicio de Publicaciones.

Cristiá, C. (2012). Sobre la interrelación de la música y la plástica en los siglos XX y XXI: Una posible tipología a partir de casos provenientes del campo artístico argentino. Trans. Revista Transcultural de Música, (16), 1- 44.

Dondis, D. A. (2000). La sintáxis de la imagen. Introducción al alfabeto visual. Barcelona: Gustavo Gili.

Frascara, J. (2006). El diseño de comunicación. Buenos Aires: Ediciones infinito.

García-Sipido, A. \& Lago, P. (1996). Color, forma, ritmo y melodía para una expresión integral. Madrid: Universidad Nacional de Educación a Distancia.
Kandinsky, V. (1998). Cursos de la Bauhaus. Madrid: Alianza. Kandinsky, V. (1996). Punto y línea sobre el plano: contribución al análisis de los elementos pictóricos. Barcelona: Paidós.

Saura, A. (2015). Dimensión formativa de la acción artística. Experiencias de construcción de conocimiento nacidas en la nube. MULTlárea. Revista de didáctica, (7), 31-78.

Toch, E. (2001). Elementos constitutivos de la música: Armonía, melodía, contrapunto y forma. Barcelona: Idea books.

Gamarra, C. (2007). El reto de la interdisciplinariedad: desde su concepción hacia la práctica pedagógica. Cuaderno de pedagogía universitaria, 4(8), 9-10. 